\title{
Peran Musik Sebagai Media Intervensi Dalam Proses Pembuatan Tato
}

\author{
Amoris \\ Program Penciptaan dan Pengkajian Musik \\ Institut Seni Indonesia Yogyakarta \\ Email: uyaumoris91@gmail.com
}

\begin{abstract}
Abstrak
Musik merupakan salah satu media yang mampu mengintervensi pendengar dalam kehidupan seharihari. Peran musik dalam berbagai aktivitas mampu memberi efek positif bagi pendengar, bahkan musik sudah lama digunakan dalam dunia medis sebagai media terapi. Penelitian ini menggunakan metode penelitian kualitatif dengan pendekatan fenomenologi. Penggunaan metode ini dengan alasan bahwa fokus dalam penelitian ini adalah untuk mendalami pengalaman seseorang atau individu terhadap intervensi musik dalam proses pembuatan tato. Hasil penelitian mengungkapkan bahwa, musik memiliki peran emosional yang mampu mengalihkan perhatian seseorang ketika di tato. Pemilihan lagu ketika ditato dianggap cukup penting dan tato artis perlu konsultasi perihal playlist lagu kepada klien. Secara garis besar, menurut hasil analisa data, klaien lebih suka mendengarkan musik yang memiliki lirik serta berkaitan dengan prilaku musikal individu.
\end{abstract}

Keywords: Role, Music Intervention, Emotional, Tattoo Process

\begin{abstract}
Music is a medium that is able to intervene its listeners in daily life. The role of music in various activities can have a positive effect on listeners, it even has been used for long time in the medical world as a therapeutic medium. This study applies qualitative research method with phenomenological approach. This method is used based on the reason that the focus of this study is to explore a person's or individual's experience of musical intervention in the tattoo-making process. The results of this study revealed that music has an emotional role in being able to distract someone when tattooed. The choice of song when tattooed is considered quite important and the artist's tattoo needs to consult about the song playlist with the client. In general, according to the results of data analysis, tattoo clients prefer listening to music with lyrics where it is related to individual musical behaviour.
\end{abstract}

Kata Kunci : Peran, Intervensi Music, Emosional, Proses tato

\section{A. Pendahuluan}

Musik telah menjadi salah satu bagian dari kehidupan manusia yang tidak terpisahkan, hampir seluruh ruang lingkup dan aktivitas manusia menggunakan musik bahkan di dalam kehidupan masyarakat adat, musik memiliki peran penting yang berkaitan dengan upacara adat dan hiburan.

Masyarakat modern menggunakan musik sebagai salah satu media hiburan yang bisa kita temukan dalam berbagai aktivitas keseharian masyarakat seperti di kantor, tempat olahraga dan tempat-tempat dimana terjadi aktivitas manusia. Musik selain 
sebagai media hiburan, beberapa musik dengan genre tertentu digunakan sebagai media terapi pasca operasi. McCaffrey et al. (2015), mengungkapkan dalam penelitiannya The Lived Experience of Listening to Music While Recovering From Surgery, membuktikan bahwa musik memiliki efek fisiologis dan psikologis positif pada pasien salah satunya musik dapat mengalihkan perhatian seseorang dari sakit. Music juga sering kali digunakan sebagai media intervensi Petri Laukka and Lina Quick, (2014), dalam penelitiannya Emotional and motivational uses of music in sports and exercise: $A$ questionnaire study among athletes mengungkapkan bahwa music meningkatkan performance, motivasi dan memiliki efek yang positif bagi atlet praperlombaan.

$$
\text { Beberapa penelitian telah }
$$
membuktikan bahwa musik memiliki pengaruh yang kuat pada kehidupan manusia secara kesehatan fisik, mental dan emosional. Intervensi musik sering dipakai untuk membangkitkan emosi tertentu, yang memudahkan manusia untuk mengingat, merasakan, dan menggali ingatan atau pengalaman yang pernah dirasakannya dan memahami peranan pengalaman tersebut dalam konteks aktual. Penggunaan musik sebagai salah satu media intervensi tentunya memiliki jenis atau genre tertentu sehingga dinilai lebih baik untuk kondisi dan kasus tertentu. Karya Wolfgang Amadeus Mozart (1756-1791) salah satu karya music yang mampu memberikan efek paling positif bagi perkembangan janin, bayi dan anakanak. Penelitian tersebut dilakukan oleh Dr. Alferd Tomatis dan Don Campbell. Mereka mengistilahkan sebagai efek Mozart. Dr. Rose Mini, A.Ap, Mpsi, berpendapat Musik sangat diperlukan bagi perkembangan bayi dan balita. Karena sejak masih dalam kandungan, bayi sudah mendengarkan ketukan musik yang berasal dari denyut jantung ibunya. Ketika seseorang mendengarkan musik, otak memproses musik tersebut di dalam auditory cortex melalui thalamus (Weinberger, 2004). Thalamus itu sendiri berada di bawah lapisan setelah cerebral cortex, yang memiliki fungsi untuk memusatkan perhatian pada stimulus sensorik tertentu (Kalat, 2004).

Penggunaan musik sebagai salah satu media intervensi dipercaya mampu memberi pengaruh positif bagi manusia, bahkan interaksi antara situasi lingkungan, dengan berbagai faktor didalamnya maupun diluar diri individu akan membentuk suatu proses kompleks yang akhirnya menentukan bentuk perilaku seseorang (Azwar, 2005). Dalam hal ini, prilaku musikal seseorang bisa terbentuk oleh 
interaksi individu dengan lingkungannya. Secara garis besar beberapa hasil penelitain sebelumnya telah menujukkan bahwa musik memiliki efek positif terhadap seseorang dalam kasus terapi musik pada dunia medis. Penggunaan musik sebagai salah satu media yang dipercaya mampu memberi pengaruh positif bagi manusia telah dikemukakan oleh peneliti-peneliti terdahulu terhadap beberapa kasus terapi musik, namun ada fenomena dimana penggunaan musik baik secara sengaja maupun tidak dilakukan dalam proses pembuatan tato pada beberapa studio tato di Yogyakarta. Hampir setiap studio tato menggunakan musik, bahkan di dalam beberapa convention tattoo internasional kita bisa menemukan musik dalam aktivitas tato yang mereka lakukan. Beberapa studio tato memutar musik tanpa kompromi dengan selera musik klien yang akan di tato, mereka suka atau tidak dengan musik yang diputar oleh studio tato tersebut. Sedangkan dalam kasus tertentu, sangat dibutuhkan jenis dan genre music yang relevan di perdengarkan, seperti pada ibu hamil, peneliti menyarankan music klasik untuk memberi efek positif kepada pasien, namun dalam kasus pembuatan tato, belum ditemukan music apa yang harus diperdengarkan kepada klien sehingga memiliki efek yang positif. Kasus ini bukanlah sesuatu yang baru, penelitipeneliti sebelumnya sudah melakukan penelitian yang serupa, namun pada obyek yang berbeda. Kehadiran musik di dalam proses pembuatan tato bukanlah sesuatu kebetulan, melainkan memiliki alasan tertentu mengapa musik tersebut dihadirkan di dalam proses pembuatan tato, namun secara spesifik kita harus mengetahui musik apa yang relevan bagi klien.

\section{Teori Emosi Schachter-Singer}

Konsep Schachter-Singer

memberikan penjelasan mengenai respon seseorang ketika mendapatkan sebuah stimulus maka terdapat dua peristiwa yaitu respon fisiologis dan intepretasi sebagai suatu reaksi. Oleh karena itu maka dapat diuraikan sebagai berikut;

1. Respon fisiologis adalah Proses fisik dalam tubuh (seperti aktivasi sistem saraf simpatik , misalnya), yang oleh para peneliti disebut sebagai "gairah fisiologis". Perubahan ini dapat mencakup hal-hal seperti jantung Anda mulai berdetak lebih cepat, berkeringat, atau gemetar. 
2. Proses kognitif, di mana orang mencoba menafsirkan respons fisiologis ini dengan melihat lingkungan sekitarnya untuk melihat apa yang dapat menyebabkan mereka merasa demikian.

\section{B. Metode Penelitian}

Penelitian ini menggunakan metode penelitian kualitatif dengan pendekatan fenomenologi. Penggunaan metode ini dengan alasan bahwa fokus dalam penelitian ini adalah untuk mendalami pengalaman seseorang atau individu terhadap intervensi musik dalam proses pembuatan tato. Kuswarno (2009), mengungkapkan bahwa fokus penelitian fenomenologi tidak hanya sekedar fenomena, akan tetapi pengalaman sadar dari sudut pandang orang pertama atau yang mengalaminya secara langsung. Penelitian ini menggunakan Teknik purposive sampling berdasarkan kriteria yang telah ditentukan. Subyek dalam penelitian ini terdiri dari 20 orang individu yang memiliki pengalaman di tato di kota Yogyakarta dengan usia 20-40 tahun. Teknik pengumpulan data yang diambil yaitu wawancara terhadap subjek yang dibantu dengan pedoman wawancara berstandar dalam bentuk pertanyaan open ended (terbuka). Metode analisi data yang digunakan yaitu deskripsi fenomena individu.

$$
\text { Penulis menggunakan tehnik }
$$
wawancara semi terstruktur dalam pengumpulan data yaitu tetap menggunakan kerangka pertanyaan penelitian namun tidak terpaku dengan pertanyaan-pertanyaan tersebut, penulis juga mengikuti arah pembicaraan narasumber untuk mendapatkan informasi lebih. Proses wawancara mendalam dilakukan secara personal kepada peserta yang sudah dipilih. Wawancara seperti ini atau personal dipilih untuk menggali kedalaman informasi terhadap narasumber. Dalam menentukan tempat dan waktu, penulis akan diskusikan dengan narasumber, untuk kenyamanan dalam melakukan wawancara. Setelah menentukan obyek yang akan diteliti, penulis akan membuat kerangka awal penelitian dengan menyusun beberapa pertanyaan terkait dengan kasus yang sedang diteliti, kerangka ini akan mempermudah penulis untuk melakukan dan menentukan siapa narasumber. Kerangka-kerangka tersebut antara lain terdiri dari menentukan narasumber, 
susunan pertanyaan wawancara dan menemukan fokus obyek yang diteliti. Setelah mendapatkan kerangka-kerangka tersebut dan fokus penelitian yang lebih detail, penulis akan melakukan wawancara. Selain penulis sendiri sebagai alat peneliti, penulis juga menggunakan alat pendukung dalam melakukan penelitian ini seperti simple note untuk mencatat poin-poin penting dalam wawancara, buku kecil yang bisa dibolak balik kan keatas untuk mempercepat penulisan, alat tulis pena, handyrecorder untuk merekam percakapan wawancara yang berlangsung dan kamera canon M3 sebagai alat perekam audio visual serta untuk foto jika diperlukan.

Setelah melakukan beberapa wawancara, penulis kemudian mereduksi dan memilih titik fokus serta membandingkan dengan data awal yang didapatkan dari melakukan kajian pustaka, apakah ada persamaan atau temuan baru yang menarik untuk diangakat menjadi sebuah masalah dalam penelitian. Dalam penelitian ini penulis melakukan wawancara terhadap 5 narasumber dengan latar belakang dan rentan umur yang berbedabeda. Penulis berhenti dengan lima orang narasumber dikarenakan informasi yang dibutuhkan sudah terpenuhi dan tercukupi. Lima orang yang dipilih sudah cukup untuk menjawab pertanyaan penelitian, untuk kajian lebih dalam lagi akan membutuhkan waktu yang cukup lama, namun dalam kebutuhan metode penelitin, hasil dari penelitian ini sudah cukup dan bisa dipertanggungjawabkan

\section{Hasil dan Pembahasan}

Penulis melakukan kode pada hasil wawancara yang sudah ditranskrip, dalam hal ini penulis mengelompokkan bagianbagian mana saja yang di anggap penting dan mengarahkan penulis menemukan jawaban dari permasalahan tersebut. Dari hasil wawancara yang dilakukan oleh penulis, terkumpul sekitar 11 kode yang menerangkan masing-masing informasi penting dalam hasil wawancara, berikut code-code tersebut:

1. Playlist : Susunan atau pilihan lagu yang dipilih

2. Mood : Suasana hati

3. Rilex : Membuat nyaman dan tenang

4. Statis : Datar atau tidak memiliki variasi

5. Musik keras : Musik yang memiliki beat cepat (rock, reagge)

6. Musik melow : Musik yang memilki beat lmbat (klasuk, instrumental) 
7. Kenangan : Ungkapan atau yang di rasakan ketika mendengarkan musik.

8. Suasana : Situasi yang terjadi saat proses pembuatan tato

9. Tato tradisional : tehnik pengerjaan tato dengan cara tradisional.

10. Studio tato : tempat pembuatan tato.

11. Tattoo artis : nama untuk profesi tato artis.

Setelah mendapatkan code-code tersebut penulis kemudian mereduksi kembali code tersebut ke dalam bentuk matriks yang disederhanakan lagi agar lebih gampang menemukan jawaban atas rumusan masalah penelitian. Code yang direduksi tersebut terdiri dari tiga yaitu musik, pengalaman, dan suasana. Dari ketiga code ini bisa mewakili keseluruhan code atau bisa dimasukkan kedalam tiga code ini. Penulis menggunakan matriks sebagai salah satu tehnik dalam mengolah data dikarenakan cara ini sangat membantu penulis dalam menemukan hasil dari penelitian yang dilakukan. Setelah melihat catatan yang terkumpul didalam matriks, penulis dapat menyimpulkan secara garis besar hasil dari penelitian ini seperti apa dan membandingkannya dengan beberapa artikel penelitian sebelumnya yang masih relevan. Berikut ini adalah data wawancara yang dimasukkan kedalam matriks:

Tabel 01. Matriks wawancara narasumber Sisca :

\begin{tabular}{|c|c|c|}
\hline & Pengalaman & Suasana \\
\hline Musik & $\begin{array}{lr}\text { Tidak suka musik- } & \text { musik statis seperti } \\
\text { lagu-lagu yang tidak } \\
\text { ada lirik atau } \\
\text { instrumental. } \\
\text { Pada saat pembuatan } \\
\text { tato lebih menyukai } \\
\text { musik-musik rock } \\
\text { stady, reagge, } \\
\text { rockabilly salah satu } \\
\text { artisnya adalah Joni } \\
\text { kesh. }\end{array}$ & $\begin{array}{l}\text { Membuat tambah } \\
\text { sakit atau susah untuk } \\
\text { mengalihkan } \\
\text { perhatian. } \\
\text { Bisa mengalihkan } \\
\text { perhatian dengan } \\
\text { mengikuti sayir lagu } \\
\text { tersebut. }\end{array}$ \\
\hline
\end{tabular}


Tabel 02. Matriks wawancara narasumber Ardo:

\begin{tabular}{|c|c|c|}
\hline & Kenangan & Suasana \\
\hline Musik & $\begin{array}{l}\text { Pada saat ditato siang } \\
\text { hari, lebih menyukai } \\
\text { musik rock, metal, } \\
\text { punk. } \\
\text { Pada malam hari lebih } \\
\text { menyukai musik } \\
\text { instrumental atau } \\
\text { musik etnis. }\end{array}$ & $\begin{array}{l}\text { Menikmati musik, } \\
\text { mengalihkan pikiran, } \\
\text { terkadang } \\
\text { membentuk inspirasi. } \\
\text { Menikmati musik, } \\
\text { mengalihkan pikiran, } \\
\text { terkadang } \\
\text { membentuk inspirasi. }\end{array}$ \\
\hline
\end{tabular}

Tabel 03. Matriks wawancara narasumber Aloy:

\begin{tabular}{|l|lr|l|}
\hline & Kenangan & Suasana \\
\hline Musik & $\begin{array}{l}\text { Tidak suka } \\
\text { mendengarkan musik } \\
\text { ketika ditato. }\end{array}$ & $\begin{array}{l}\text { Lebih menikmati rasa } \\
\text { sakit ditato. }\end{array}$ \\
\hline
\end{tabular}

Tabel 04. Matriks wawancara narasumber Asti :

\begin{tabular}{|l|l|l|}
\hline & Kenangan & Suasana \\
\hline Musik & $\begin{array}{l}\text { Ketika ditato lebih } \\
\text { menyukai musik klasik, } \\
\text { instrumental, musik- } \\
\text { musik yang selow tidak } \\
\text { terlalu ngebeat. }\end{array}$ & $\begin{array}{l}\text { Membangun suasana, } \\
\text { bikin rilex. }\end{array}$ \\
& $\begin{array}{l}\text { Lagu-lagu yan sedang } \\
\text { hits, lebih menyukai } \\
\text { musik EDM. }\end{array}$ & $\begin{array}{l}\text { Membentuk mood } \\
\text { menjadi lebih baik. }\end{array}$ \\
\hline
\end{tabular}

Tabel 05. Matriks wawancara narasumber Herpianto Hendra :

\begin{tabular}{|l|l|l|}
\hline & Kenangan & Suasana \\
\hline Musik & $\begin{array}{l}\text { Lebih menyukai musik } \\
\text { rock dan reagge. }\end{array}$ & $\begin{array}{l}\text { Mengikatkan mood } \\
\text { dan semangat. } \\
\text { Ketika pembuatan tato } \\
\text { tradisioanl lebih } \\
\text { menyukai musik tradisi } \\
\text { seperti jonggan dan semangat. } \\
\text { musik sape'. }\end{array}$ \\
\hline
\end{tabular}


Terdapat beberapa asumsi mengenai hasil akhir dari penelitian ini yang didapatkan dari beberapa literature yang relevan dengan kasus ini. Asumsi sementara yang dibangun oleh penulis sebelum melakukan wawancara adalah bahwa penggunaan musik dalam pembuatan tato berfungsi sebagai pengalih perhatian klien dari rasa sakit. Selain itu penulis juga mengacu pada beberapa hasil penelitian yang mengungkapkan hal yang sama dalam penelitian mereka bahwa musik dianggap memiliki banyak efek pada tubuh. Setelah membuat beberapa kerangka wawancara, penulis kemudian menentukan narasumber yang akan diwawancara. Dalam menentukan narasumber penulis menekankan pada beragam latarbelakang profesi atau pekerjaan apa yang sedang mereka tekuni, hal ini dilakukan guna mendapatkan bermacam argumen mengenai pengalaman mereka. Setelah melakukan wawancara, penulis memutuskan untuk mencukupkan wawancara kepada 20 Narasumber. Ke-20 narasumber ini memiliki latarbelakang yang berbeda-beda yaitu musisi, fotografi, ibu rumah tangga, admin, mahasiswa dan tattoo artist.

Penulis menemukan beberapa hasil jawaban yang bervariasai namun bisa ditarik benang merah dari ke-20 narasumber tersebut. Beberapa narasumber memiliki ketertarikan dan pendapat yang sama mengenai pengalaman mereka di tato dengan intervensi musik pada saat di tato. Terdapat 16 orang dari 20 berpendapat bahwa musik dalam pengerjaan tato sangat membantu dalam membuat mood menjadi enak, mengalihkan perhatian dari rasa sakit dan membuat lebih rilex. Pendapat bersebrangan datang dari 4 narasumber yang diwawancara. mereka mengatakan bahwa dalam pengerjaan tato, mereka tidak terlalu memperhatikan musik dan musik tidak terlalu penting baginya. Jika asumsi penulis sebelumnya musik digunakan untuk mengalihkan perhatian rasa sakit, namun untuk kasus 4 narasumber ini berbeda, mereka membuat tato dikarenakan ingin merasakan sakit yang dihasilkan oleh goresan jarum tato pada kulit serta rasa penasaran dan ingin menato diri mereka dengan gambar yang lebih banyak. Namun mereka juga tetap berpendapat bahwa, music kemungkinan memiliki peran yang cukup membantu dalam proses tato namun mereka tidak fokus pada musiknya melainkan pada proses pengerjaan tato yang berlangsung.

Penulis menggunakan matriks sebagai salah satu tehnik dalam mengolah data dikarenakan cara ini sangat membantu penulis dalam menemukan hasil dari 
penelitian yang dilakukan. Setelah melihat catatan yang terkumpul didalam matriks, penulis dapat menyimpulkan secara garis besar hasil dari penelitian ini seperti apa dan membandingkannya dengan beberapa artikel penelitian sebelumnya yang masih relevan. Berikut ini adalah beberapa data wawancara yang dimasukkan kedalam matriks:

Pengalaman narasumber Sisca :

\begin{tabular}{|c|c|c|}
\hline & Pengalaman & Suasana \\
\hline Musik & $\begin{array}{l}\text { Tidak suka musik-musik statis seperti lagu- } \\
\text { lagu yang tidak ada lirik atau instrumental. } \\
\text { Pada saat pembuatan tato lebih menyukai } \\
\text { musik-musik rock stady, reagge, rockabilly } \\
\text { salah satu artisnya adalah Joni kesh. } \\
\text { Pada saat ditato siang hari, lebih menyukai } \\
\text { musik rock, metal, punk. } \\
\text { Pada malam hari lebih menyukai musik } \\
\text { instrumental atau musik etnis. } \\
\text { Tidak suka mendengarkan musik ketika } \\
\text { ditato. } \\
\text { Ketika ditato lebih menyukai musik klasik, } \\
\text { instrumental, musik-musik yang selow tidak } \\
\text { terlalu ngebeat. } \\
\text { Lagu-lagu yang sedang hits, lebih menyukai } \\
\text { musik EDM. }\end{array}$ & $\begin{array}{l}\text { Membuat tambah sakit atau susah untuk } \\
\text { mengalihkan perhatian. } \\
\text { Bisa mengalihkan perhatian dengan } \\
\text { mengikuti sayir lagu tersebut. } \\
\text { Menikmati musik, mengalihkan pikiran, } \\
\text { terkadang membentuk inspirasi. } \\
\text { Menikmati musik, mengalihkan pikiran, } \\
\text { terkadang membentuk inspirasi. } \\
\text { Lebih menikmati rasa sakit ditato. } \\
\text { Mengikatkan mood dan semangat. } \\
\text { Membentuk mood menjadi lebih baik. }\end{array}$ \\
\hline
\end{tabular}


Narasumber memiliki jawaban yang mendekati dengan hasil penelitian sebelumnya dengan kasus berbeda yaitu yang dilakuan pada dunia medis dengan narasumber pasien yang sakit. Menurut Ruth G. McCaffrey et al. (2015). Dalam penelitian nya disebutkan bahwa musik dapat mengalihkan perhatian pasien dan meningkatkan respon relaksasi dan dengan demikian mengurangi rasa sakit. Hasil penelitian tersebut memiliki kesamaan dengan hasil penelitian yang dilakukan oleh penulis yaitu dalam merekam pengalaman seseorang yang mendengarkan musik ketika ditato. Kasus ini memiliki kesamaan yaitu musik berfungsi sebagai pengalih perhatian seseorang dari rasa sakit. Musik bekerja sebagai pengalih rasa sakit serta membuat rilex narasumber dan membangun mood tato artis yang bekerja. Hasil akhir dari penelitian ini yang didapatkan dari beberapa literature yang relevan dengan kasus ini. Asumsi sementara yang dibangun oleh penulis sebelum melakukan wawancara adalah bahwa penggunaan musik dalam pembuatan tato berfungsi sebagai pengalih perhatian klien dari rasa sakit. Selain itu penulis juga mengacu pada beberapa hasil penelitian yang mengungkapkan hal yang sama dalam penelitian mereka bahwa musik dianggap memiliki banyak efek pada tubuh.
Setelah membuat beberapa kerangka wawancara, penulis kemudian menentukan narasumber yang akan diwawancara. Dalam menentukan narasumber penulis menekankan pada beragam latarbelakang profesi atau pekerjaan apa yang sedang mereka tekuni, hal ini dilakukan guna mendapatkan bermacam argumen mengenai pengalaman mereka. Setelah melakukan wawancara, penulis memeutuskan untuk mencukupkan wawancara kepada narasumber. Kelima narasumber ini memiliki latarbelakang yang berbeda yaitu ada yang dari musik, fotografi, ibu rumah tangga, admin, dan tattoo artist.

Beberapa hasil jawaban yang bervariasai namun bisa ditarik benang merah dari kelima narasumber tersebut. ada beberapa orang yang memiliki ketertarikan yang sama dengan jenis musik yang diputar dan dari 5 orang ini 4 orang mengatakan bahwa musik dalam pengerjaan tato sangat membantu dalam membuat mood menjadi enak, mengalihkan perhatian dari rasa sakit dan membuat lebih rilex. Pendapat bersebrangan datang dari narasumber Aloy, beliau mengatakan bahwa dalam pengerjaan tato, dia tidak terlalu memperhatikan musik dan musik tidak terlalu penting baginya. Jika asumsi penulis sebelumnya musik digunakan untuk mengalihkan perhatian 
rasa sakit, namun untuk kasus Aloy, dia membuat tato lagi dan lagi dikarenakan ingin merasakan sakit yang dihasilkan oleh goresan jarum tato pada kulit. Namun dia tetap mengatakan bahwa mungkin untuk beberapa orang musik memilki peran yang cukup membantu dalam pengejaan tato.

Setelah mereduksi hasil wawancara, narasumber memiliki jawaban yang mendekati dengan hasil penelitian sebelumnya dengan kasus berbeda yaitu yang dilakuan pada dunia medis dengan narasumber pasien yang sakit. Menurut penelitian nya disebutkan bahwa musik dapat mengalihkan perhatian pasien dan meningkatkan respon relaksasi dan dengan demikian mengurangi rasa sakit Ruth G. McCaffrey et al. (2015). Hasil penelitian tersebut memiliki kesamaan dengan hasil penelitian yang dilakukan oleh penulis yaitu dalam merekam pengalaman seseorang yang mendengarkan musik ketika ditato. Kasus ini memiliki kesamaan yaitu musik berfungsi sebagai pengalih perhatian seseorang dari rasa sakit. Musik bekerja sebagai pengalih rasa sakit serta membuat rilex narasumber dan membangun mood tato artis yang bekerja.

\section{Simpulan}


penelitian dengan menyusun beberapa pertanyaan terkait dengan kasus yang sedang diteliti, kerangka ini akan mempermudah penulis untuk melakukan dan menentukan siapa narasumber. Kerangka-kerangka tersebut antara lain terdiri dari menentukan narasumber, susunan pertanyaan wawancara dan menemukan fokus obyek yang diteliti. Setelah mendapatkan kerangka-kerangka tersebut dan fokus penelitian yang lebih detail, penulis akan melakukan wawancara. Selain penulis sendiri sebagai alat peneliti, penulis juga menggunakan alat pendukung dalam melakukan penelitian ini seperti simple note untuk mencatat poin-poin penting dalam wawancara, buku kecil yang bisa dibolak balik kan keatas untuk mempercepat penulisan, alat tulis pena, handyrecorder untuk merekam percakapan wawancara yang berlangsung dan kamera canon M3 sebagai alat perekam audio visual serta untuk foto jika diperlukan .

Setelah melakukan beberapa wawancara, penulis kemudian mereduksi dan memilih titik fokus serta membandingkan dengan data awal yang didapatkan dari melakukan kajian pustaka, apakah ada persamaan atau temuan baru yang menarik untuk diangakat menjadi sebuah masalah dalam penelitian. Dalam penelitian ini penulis melakukan wawancara terhadap 5 narasumber dengan latar belakang dan rentan umur yang berbedabeda. Penulis berhenti dengan lima orang narasumber dikarenakan informasi yang dibutuhkan sudah terpenuhi dan tercukupi. Lima orang yang dipilih sudah cukup untuk menjawab pertanyaan penelitian, untuk kajian lebih dalam lagi akan membutuhkan waktu yang cukup lama, namun dalam kebutuhan metode penelitin, hasil dari penelitian ini sudah cukup dan bisa dipertanggung jawabkan.

Penggunaan musik dalam peroses pembuattan tato memiliki beberapa fungsi, yang pertama dalah untukmembangkitkan mood serta semangat tattoo artis dalam bekerja atau menato, kemudian yang kedua adalah membantu mengalihkan rasa sakit ketika ditato. Penulis menemukan 4 jawaban yang mengatakan dalam wawancara bahwa musik membantu mereka mengalihkan perhatian mereka terhadap sakit dalam pembuatan tato. Musik yang memiliki lirik sangat membantu karena narasumber atau klien bisa mengikuti setip lirik dari lagu tersebut sehingga pikiran mereka teralihkan dan fokus pada musik yang sedang diputar.

Penggunaan musik dalam peroses pembuattan tato memiliki beberapa peran, yang pertama dalah untuk membangkitkan mood serta semangat tato artis dalam 
bekerja atau menato, kemudian yang kedua adalah membantu mengalihkan rasa sakit ketika ditato. Penulis menemukan empat belas jawaban yang mengatakan dalam wawancara bahwa musik membantu mereka mengalihkan perhatian terhadap sakit dalam pembuatan tato. Musik yang memiliki lirik sangat membantu mengalihkan perhatian dari sakit atau klien bisa mengikuti setip lirik dari lagu tersebut sehingga pikiran mereka teralihkan dan fokus pada musik yang sedang diputar.

Ada beberapa jenis musik yang menjadi kesukaan narasumber ketika ditato diantaranya adalah musik rock, reagge, EDM serta musik-musik yang memiliki beat cepat seperti karya Jhony Cash; Ghost iders in the sky, Metallica; enter sandman, Dream theater; Metropolis, Yellow Clow ; Till it hurts, Avenged Sevenfold; Dear God dan Bob Marley; No Woman No Cry. Walaupun demikian, terdapat enam orang klien yang fleksibel dalam memilih musik ketika ditato, terkadang suka dengan musikmusik instrumental seperti musik klasik terkadang genre music rock dan reggae. Secara garis besar musik dalam pembuatan tato memiliki peran penting dalam mengalihkan perhatian narasumber terhadap efek sakit yang ditimbulkan ketika ditato

\section{E. Daftar Pustaka}

AA Faraj et al. (January 2014), "Listen while you work? The attitude of healthcare professionals to music in the operating theatre ", $S A G E$ jurnal.

Azwar, S. (2005). Sikap Manusia : Teori dan Pengukurannya. Yogyakarta : Pustaka Pelajar

Djohan (2006). Terapi musik: Teori dan Aplikasi. Yogyakarta: Percetakan Galangpress.

Fenko Anna et al. (April 2014), "The Influence of Ambient Scent and Music on Patients' Anxiety in a Waiting Room of a Plastic Surgeo", Sage.

Kalat, J. W. (2004). Biological psychology (Edisi kedelapan). Belmont, CA: Wadsworth Publishing.

Kuswarno, Engkus (2009), Metodologi Penelitian Komunikasi Fenomenologi; Konsepsi, Pedoman, dan Contoh Penelitian, Bandung: Widya Padjajaran

Laukka Petri et al. (2014), "Emotional and motivational uses of music in sports and exercise", Psychology of Music, 41 (2)198-215.

McCaffrey Ruth G. et al. (2001), " The Lived Experience of Listening to Music While Recovering From Surgery ", Journal of Holistic Nursing, 18 (4): 374-90.

McCaffrey Ruth G. et al. (Maret 2015), “The Lived Experience of Listening to Music While Recovering From Surgery ", Sage Publication 
Hekmat Hamid M et al. (2014) "Pain Attenuating Effects of Preferred Versus Non preferred Music Interventions". Sage Jurnal Publication.

Torre-Luque Alejandro de la, et al. (2017) "Effects of preferred relaxing music after acute stress exposure: $A$ randomized controlled trial ", Psychology of Musics. 795-813

Weinberger, N. M. (2004). "Music and the Brain”. Scientific American. 291(5), 88- 95. 